\title{
Há um Português na "Origem" do Prémio Nobel da Química 2019
}

A Real Academia Sueca das Ciências anunciou, em outubro de 2019, a atribuição do Prémio Nobel da Química 2019 a John B. Goodenough (Universidade do Texas, Austin, EUA), M. Stanley Whittingham (Universidade de Binghamton, Nova lorque, EUA) e Akira Yoshino (Asahi Kasei Corporation, Tóquio, Japão e Universidade Meijo, Nagoya, Japão) pelo "desenvolvimento das baterias de iões lítio".

(c) Nobel Media.

Photo: A. Mahmoud

John B. Goodenough

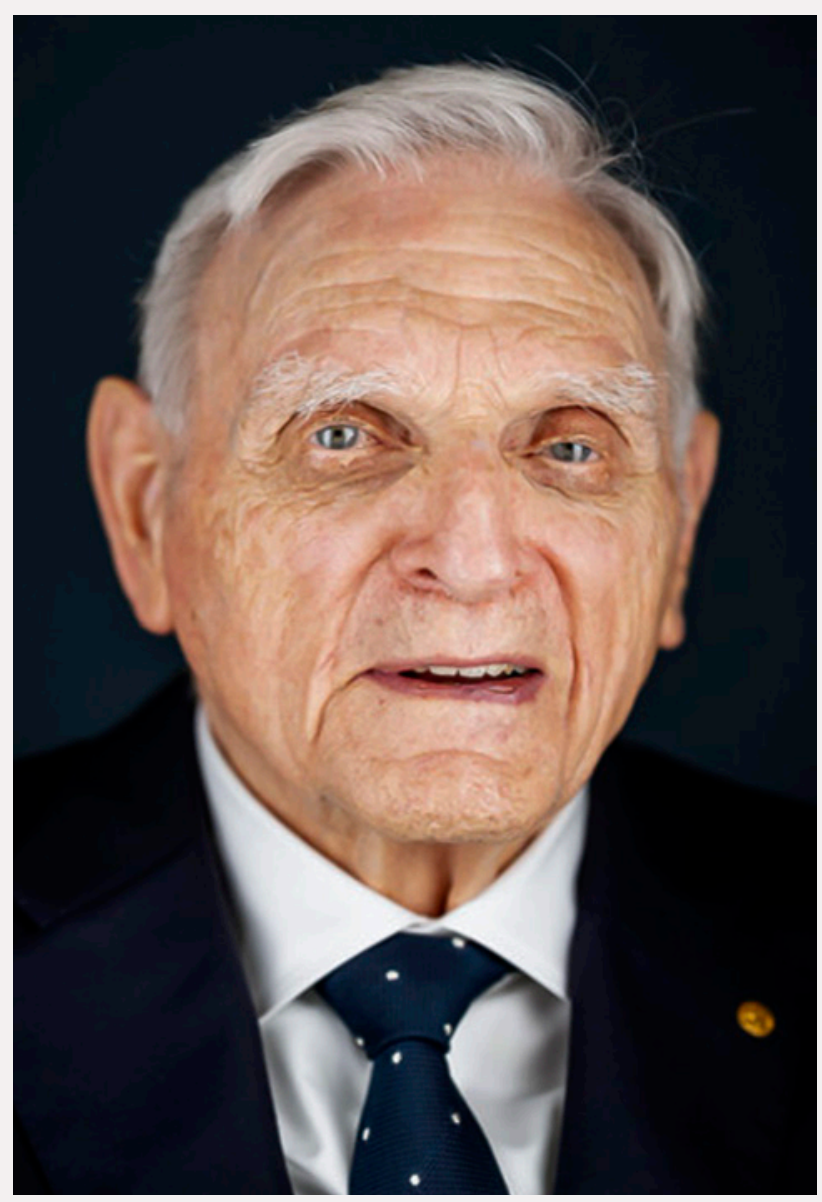

Os seus estudos levaram ao aparecimento de baterias comerciais de lítio em 1991. Comparada com outras baterias comercialmente disponíveis à época, a bateria de lítio tornou-se rapidamente muito competitiva e abriu caminho à revolução, nomeadamente, nos equipamentos eletrónicos de comunicação móvel, computadores e outros dispositivos eletrónicos e veículos elétricos.

O lítio, do grego lithos que significa pedra, foi descoberto em 1818 pelo jovem de 25 anos Johan August Arfwedson, quando trabalhava no laboratório de Berzelius. Numa carta para Claude Louis Berthollet escrita a 9 de fevereiro de 1818, Berzelius relata que "o novo álcali foi descoberto pelo Sr. Arfwedson (...) num mineral previamente descoberto pelo Sr. d'Andrada numa mina de Utö e por ele chamado de petalite (...)" O Sr. d'Andrada mencionado era José Bonifácio de Andrada e Silva...

221 anos após a descoberta da petalite pelo português José Bonifácio de Andrada e Silva*, e 203 anos depois da descoberta do lítio pelo jovem sueco Johan August Arfwedson celebrámos em 2019 o Ano Internacional da Tabela Periódica proclamado pela UNESCO. Com o objetivo de alertar a população que o bem-estar da Humanidade no planeta, e o funcionamento da economia dependem da utilização responsável dos recursos naturais, a sustentabilidade deve recorrer a novas tecnologias sem causar danos ambientais. 


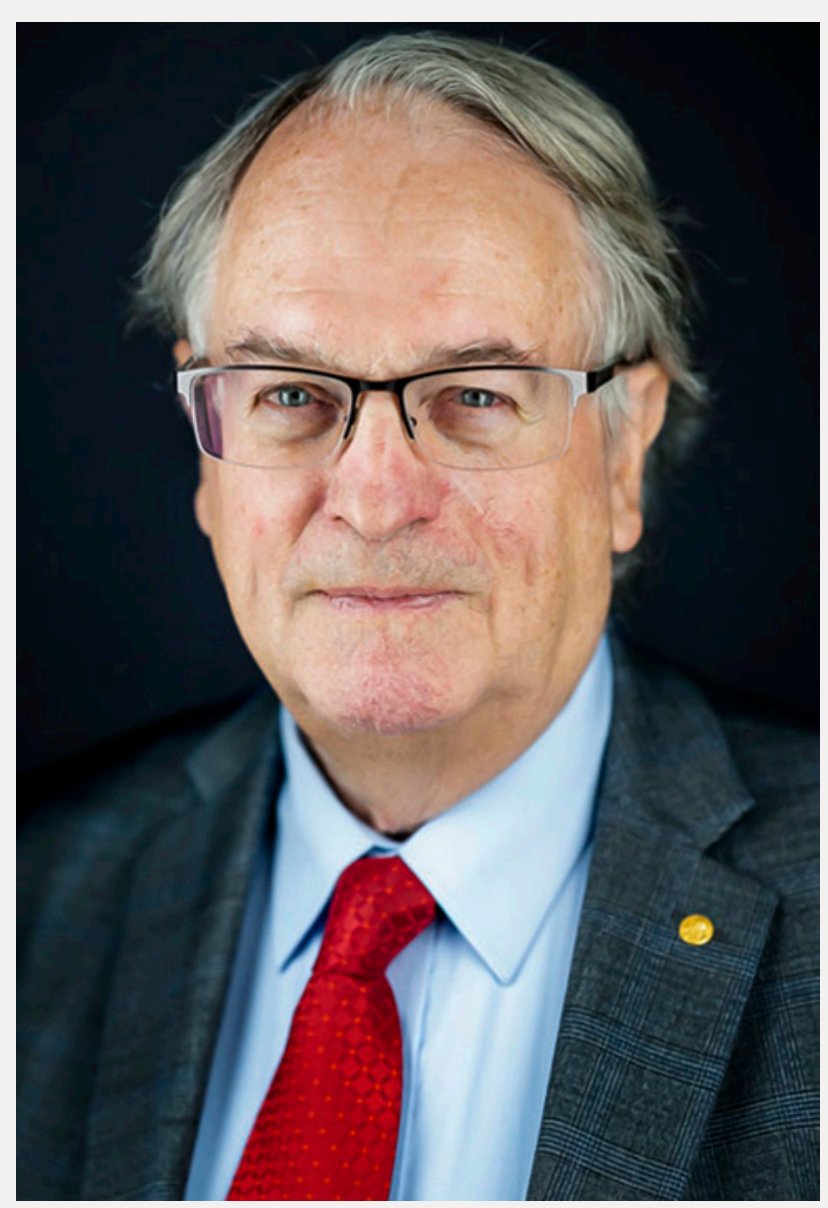

(c) Nobel Media

Photo: A. Mahmoud M.

Stanley Whittingham reconhecer a contribuição diária da Química e dos Processos Químicos e demonstrar que a dependência por estes dispositivos (em especial nas camadas mais jovens) só será possível com uma atitude de reduzir os desperdícios, e reutilizar e reciclar os recursos ainda disponíveis.

Quando, no início da década de 90 as baterias secundárias (recarregáveis) de Ni-Cd estavam a começar a ser substituídas pelas de $\mathrm{Ni}-\mathrm{MH}$ (MH-hidreto metálico), mais eficientes e ecológicas mas recorrendo a uma tecnologia idêntica, surgiram as baterias de ião lítio que vieram mudar todo o paradigma do armazenamento de energia, tendo catapultado a utilização de dispositivos pessoais com elevada autonomia energética. Registou-se um verdadeiro salto quântico na evolução dos sistemas de armazenamento de energia e esta merecida distinção a estes três brilhantes investigadores pela academia sueca, só peca por tardia.

O lítio sempre foi reconhecido como um elemento com elevadíssimo interesse para o desenvolvimento de baterias, dado o apelativo valor de potencial da sua conversão eletroquímica. Estas características perspetivaram a conceção de baterias com muito elevada densidade de energia, como veio a acontecer. Para tal tiveram que ser ultrapassados vários problemas como a utilização segura de um elemento tão reativo no estado elementar, a limitada solubilidade de sais de lítio nos meios não aquosos, a eficiência do processo catódico, a rápida degradação dos elétrodos quando sujeitos a repetidos processos de carga/descarga, etc. Foi aqui que os laureados tiveram, cada um deles, um papel fundamental na utilização diária (imprescindível) que atribuímos a estes dispositivos. Ainda na década de 70, M. Stanley Whittingham desenvolveu materiais de cátodo que permitiram a intercalação de iões lítio durante a descarga da bateria, não elevando assim para valores críticos a sua concentração no eletrólito. Os cátodos sofreram ainda posteriores evoluções pela mão de John Goodenough que 
utilizou materiais da mesma família química ou de famílias afins (espinelas) mas que proporcionaram ainda mais energia a estas unidades, materiais esses que ainda são usados nas baterias atuais. Já Akira Yoshino esteve particularmente dedicado ao ânodo e aos problemas associados à utilização do lítio metálico. Foi graças a ele que se desenvolveram os materiais grafíticos capazes de intercalar lítio que hoje utilizamos com toda a segurança.

É, no entanto, irónico, que assistamos agora a este reconhecimento pela valia dos trabalhos destes três cientistas no domínio das baterias de ião lítio, quando a comunidade científica começa a procurar alternativas a estes dispositivos. Com efeito, as limitadas reservas naturais deste elemento associada à natureza recalcitrante de muitos dos seus minerais estão a conduzir a um crescente custo do lítio e a uma contínua exaustão do recurso. Uma das alternativas muito promissoras são as baterias de ião sódio (elemento muito abundante na natureza) embora ainda persistam alguns problemas associados à sua utilização, que terão de ser resolvidos. De qualquer forma, a tecnologia associada às futuras unidades de armazenamento de energia terá sempre a génese dos trabalhos pioneiros destes três cientistas, a quem a sociedade atual muito deve.

\section{Maria José Lourenço e Jorge Correia}

mjlourenco@ciencias.ulisboa.pt

jmcorreia@ciencias.ulisboa.pt *em 1804 era o diretor do Laboratório Químico da Casa da Moeda, situado à data na Rua de São Paulo em Lisboa e o Intendente Geral das Minas e Metais do Reino, uma figura de reconhecidos méritos sobretudo na mineralogia e na metalurgía.

Recentemente José Bonifácio de Andrada e Silva passou a ser considerado oficialmente o Patrono da Independência do Brasil pela lei 13.615/2018 (Art. 1º, 0 estadista José Bonifácio de Andrada e Silva é declarado Patrono da Independência do Brasil .. Brasília, 11 de janeiro de 2018); esta lei teve origem no Projeto de Lei da Câmara (PLC) 94/2017, aprovado em dezembro de 2017 no Senado Federal e publicada no Diário Oficial da União.

Mais informações in Sandra de Oliveira Franco Patrocínio, "José Bonifácio de Andrada e Silva e os estudos Químico-Mineralógicos: uma vida perpassada por compromissos com o Ensino e a Sociedade", Dissertação de Mestrado, 2015.

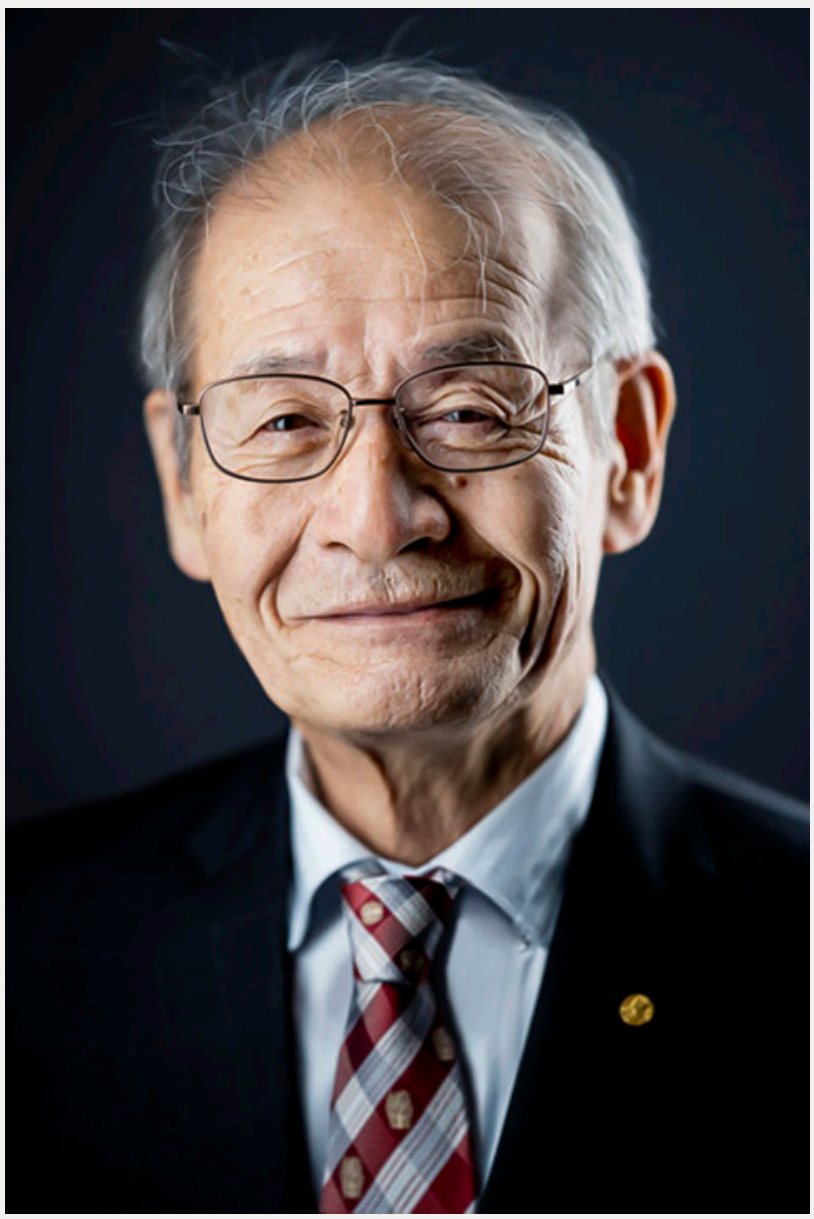
Akira Yoshino 